ARTICLE

https://doi.org/10.1038/s41467-019-10504-6

\title{
Two-dimensional semiconducting covalent organic frameworks via condensation at arylmethyl carbon atoms
}

Shuai Bi (1) ${ }^{1}$, Can Yang ${ }^{2}$, Wenbei Zhang ${ }^{1}$, Junsong $\mathrm{Xu}^{1}$, Lingmei Liu (iD ${ }^{3}$, Dongqing $\mathrm{Wu}^{1}$, Xinchen Wang ${ }^{2}$, Yu Han (1) ${ }^{3}$, Qifeng Liang ${ }^{4} \&$ Fan Zhang (1) ${ }^{1}$

Construction of organic semiconducting materials with in-plane $\pi$-conjugated structures and robustness through carbon-carbon bond linkages, alternatively as organic graphene analogs, is extremely desired for powerfully optoelectrical conversion. However, the poor reversibility for $\mathrm{sp}^{2}$ carbon bond forming reactions makes them unavailable for building high crystalline well-defined organic structures through a self-healing process, such as covalent organic frameworks (COFs). Here we report a scalable solution-processing approach to synthesize a family of two-dimensional (2D) COFs with trans-disubstituted $\mathrm{C}=\mathrm{C}$ linkages via condensation reaction at arylmethyl carbon atoms on the basis of 3,5-dicyano-2,4,6trimethylpyridine and linear/trigonal aldehyde (i.e., 4,4"-diformyl-p-terphenyl, 4,4'-diformyl1,1'-biphenyl, or 1,3,5-tris(4-formylphenyl)benzene) monomers. Such $s p^{2}$ carbon-jointedpyridinyl frameworks, featuring crystalline honeycomb-like structures with high surface areas, enable driving two half-reactions of water splitting separately under visible light irradiation, comparable to graphitic carbon nitride $\left(\mathrm{g}-\mathrm{C}_{3} \mathrm{~N}_{4}\right)$ derivatives.

\footnotetext{
${ }^{1}$ School of Chemistry and Chemical Engineering, State Key Laboratory of Metal Matrix Composites, Shanghai Jiao Tong University, 200240 Shanghai, China. ${ }^{2}$ State Key Laboratory of Photocatalysis on Energy and Environment, College of Chemistry, Fuzhou University, 350002 Fuzhou, China. ${ }^{3}$ Advanced Membranes and Porous Materials Center, Physical Sciences and Engineering Division, King Abdullah University of Science and Technology (KAUST), Thuwal 23955-6900, Saudi Arabia. ${ }^{4}$ Department of Physics, Shaoxing University, 312000 Shaoxing, China. Correspondence and requests for materials should be addressed to X.W. (email: xcwang@fzu.edu.cn) or to F.Z. (email: fan-zhang@sjtu.edu.cn)
} 
R ecently, 2D organic porous materials with well-defined $\pi$ extended structures, emerging as organic graphene analogs, have been successfully synthesized by connecting organic building blocks through carbon-carbon bond linkages ${ }^{1-3}$. They inherit the structural merits of graphene and $\pi$-conjugated organic molecules to some extent, promising for applications in optoelectronic and energy-storage devices 4,5 . Among these materials, a nano-porous graphene and a $2 \mathrm{D}$ conjugated aromatic polymer with carbon-carbon single bond $(\mathrm{C}-\mathrm{C})$ linkages have been synthesized through surface-mediated polymerization and solid-state topochemical polymerization, respectively ${ }^{6,7}$. In studies on these materials, rationally designed monomers for preassembly and precise regioselective coupling polymerization act as key roles in the formation of architectures with excellent topologies. In another case, we reported a 2D cyanostilbene-based covalent organic framework (COF) involving the connection of aromatic units through a carbon-carbon double bond $(\mathrm{C}=\mathrm{C})$ linkage under the Knoevenagel reaction (Fig. 1a) ${ }^{8}$. This report suggested that carbon-carbon bonding enables a system to undergo a thermodynamically controlled process, in which the crystallinity of an in-plane structure is governed through continued 2D chain growth and defect correction, as verified in the previously reported COFs with dynamic covalent linkages (e.g., imine $)^{9}$. Afterwards, another 2D cyanostilbene-based COF was developed through a similar preparation protocol by using pyrene as one of the building blocks (Fig. 1a) ${ }^{10}$. Such kind of COFs exhibit $\pi$-delocalization over $2 \mathrm{D}$ networks, attributed to the efficient $\pi$-electron communication through $\mathrm{C}=\mathrm{C}$ linkages, as verified by numerous $\mathrm{C}=\mathrm{C}$-containing artificial organic compounds and natural products (e.g., $\beta$-carotene) with unique photophysical properties. In a Knoevenagel reaction, the aryl $\alpha$-carbon atom in a monomer can be easily converted to a reactive intermediate carbanion, which tends to be stabilized through a $p$ - $\pi$-conjugated effect $^{11}$. This carbanion can definitely promote the formation of a highly crystalline structure through self-healing processes. On the other hand, a $\mathrm{C}=\mathrm{C}$ linkage enables avoiding the twisted conformations arising from steric repulsion in a main backbone when two aromatic units are directly coupled by a $\mathrm{C}-\mathrm{C}$ single bond, thus beneficial to the formation of an in-plane $\pi$-conjugated structure. Nevertheless, it would be challenging to determine appropriate conditions or regulation for reversible $\mathrm{C}=\mathrm{C}$ bond formation, even in the aforementioned Knoevenagel reactions, which, according to our knowledge, only succeeded for a few COF samples arising from 1,4-phenylenediacetonitrile (or its derivatives).

Owing to the highly exposed surface areas and tunable band gaps, polymeric semiconductors such as graphitic carbon nitride $\left(\mathrm{g}-\mathrm{C}_{3} \mathrm{~N}_{4}\right)$ have been attracting considerable attention as highperformance photocatalysts for water splitting under visible light, which is one of the long-term goals for the efficient storage of intermittent solar energy ${ }^{12-20}$. The high crystallinity of 2D COFs has substantial advantages with respect to their well-defined structures, which can facilitate establishing structure-property relationships and provide insights into photocatalytic processes or mechanisms ${ }^{21-24}$. Attempts to promote the photocatalytic activities for COFs have mainly been hindered by their relatively low stability and poor $\pi$-electron delocalization ${ }^{25,26}$. Pyridine derivatives as nitrogen-embedded aromatic units feature Lewis basicity and versatile optoelectronic properties. In particular, completely different from the interrupted conjugation effect on the meta-positions of phenyl ring, the facile modification of pyridine in its 2,6-positions, 2,5-positions, or 2,4-positions enables achieving well extended $\pi$-conjugated systems, thus extensively used as building blocks or ligands for constructing organic or organometallic semiconductors with excellent photocatalytic behaviors ${ }^{27,28}$. a

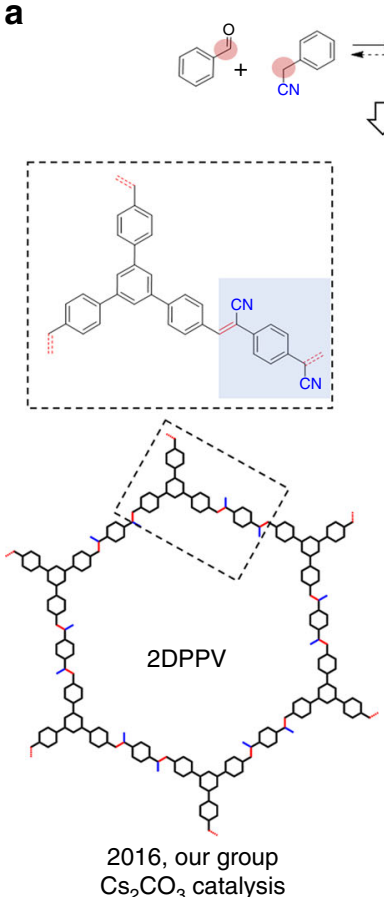

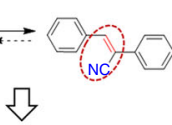
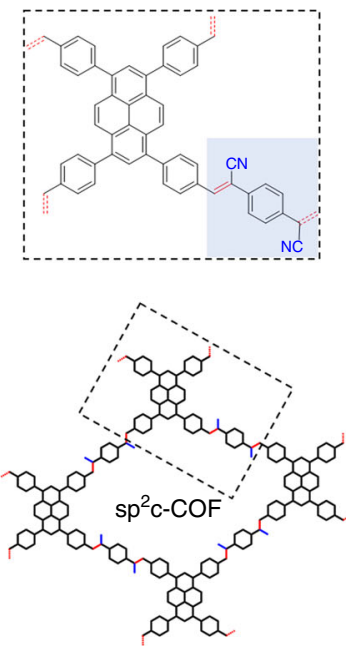

2017, Jiang et al. $\mathrm{NaOH}$ catalysis
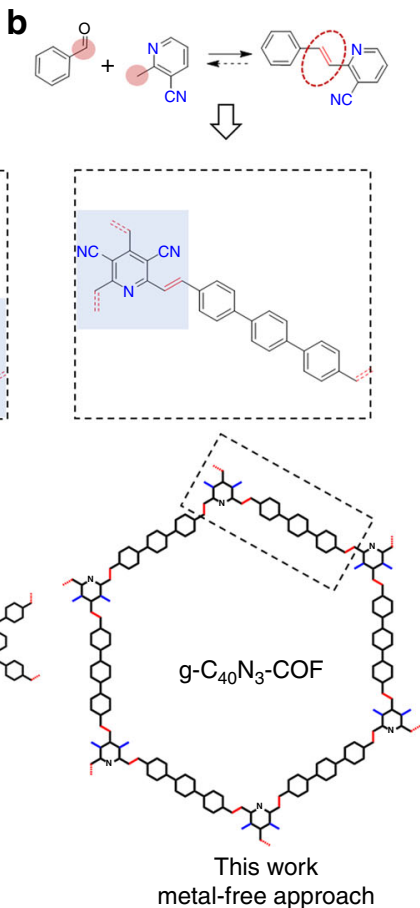

Fig. 1 Chemical structures of the $C=C$ bond linked covalent organic frameworks. a Representative two examples of 2D covalent organic frameworks with carbon-carbon double bond $(\mathrm{C}=\mathrm{C})$ linkages through Knoevenagel condensation at methylene carbon atoms by using inorganic base catalysts. $\mathbf{b}$ Metalfree approach to the target $2 \mathrm{D}$ covalent organic framework ( $\mathrm{g}-\mathrm{C}_{40} \mathrm{~N}_{3}-\mathrm{COF}$ ) with $\mathrm{C}=\mathrm{C}$ linkages via condensation at arylmethyl carbon atoms upon organic base catalysis 
In this study, we utilize 3,5-dicyano-2,4,6-trimethylpyridine (DCTMP) as the key building block, whose three methyl carbon atoms are readily converted to relatively stable carbanions under an organic base catalyst in a p- $\pi$-conjugated system ${ }^{29,30}$. Upon condensation with 4,4"-diformyl-p-terphenyl (DFPTP), 4,4'diformyl-1,1'-biphenyl (DFBP) and 1,3,5-tris(4-formylphenyl) benzene (TFPB) in N,N-dimethylformamide (DMF), three 2D COFs (denoted as $\mathrm{g}-\mathrm{C}_{\mathrm{x}} \mathrm{N}_{\mathrm{y}}$-COFs) with trans-disubstituted $\mathrm{C}=\mathrm{C}$ bond linkages are formed in nearly quantitative yields, termed as g- $\mathrm{C}_{40} \mathrm{~N}_{3}$-COF, g- $\mathrm{C}_{31} \mathrm{~N}_{3}$-COF, and $\mathrm{g}^{-} \mathrm{C}_{37} \mathrm{~N}_{3}$-COF, respectively. Powder X-ray diffraction (PXRD), high-resolution transmission electron microscopy (HRTEM), and surface area measurement clearly reveal the COFs have honeycomb-like crystalline porous structure with high surface areas. The appropriate energy levels of conduction and valence bands of g- $\mathrm{C}_{40} \mathrm{~N}_{3}$-COF allow for driving two half-reactions of water splitting separately to generate hydrogen or oxygen under visible light irradiation.

\section{Results}

Design and synthesis of $\mathbf{g}-\mathrm{C}_{\mathbf{x}} \mathrm{N}_{\mathbf{y}}-\mathrm{COFs}$. The target COFs were solvothermally synthesized through Knoevenagel condensation reaction between 3,5-dicyano-2,4,6-trimethylpyridine (DCTMP) and linear/trigonal aldehyde (4,4"-diformyl-p-terphenyl, 4, $4^{\prime}$ diformyl-1,1'-biphenyl or 1,3,5-tris(4-formylphenyl)benzene) in $\mathrm{DMF}$, catalyzed by the organic base piperidine. In this process, first, the pyridinyl methyl carbon atoms in DCTMP are converted to carbanions through $\mathrm{C}-\mathrm{H}$ cleavage upon treatment with the base. This conversion is typically attributed to a decline in the electronic cloud density around these arylmethyl carbon atoms, which is caused by the strong electron-deficient pyridine ring that bears two electron-withdrawing cyano groups. The resulted carbanions tend to be stabilized through a strong $p$ - $\pi$-conjugated interaction with this substituted pyridine ring, enabling the subsequent nucleophilic attacks on the positive carbon atoms in the aromatic formyl groups of these aldehydes. Such attacks form carbon-carbon bonds, which then transform to carbon-carbon double bonds by releasing $\mathrm{H}_{2} \mathrm{O}$ molecules. Under the guidance of such a reaction mechanism, we established an appropriate condition for achieving high-crystalline olefin-linked COFs. For example, in an optimized procedure, DCTMP (0.50 mmol), DFPTP $(0.75 \mathrm{mmol})$, and piperidine $(3.00 \mathrm{mmol})$ were dissolved in DMF $(10 \mathrm{~mL})$ and employed in a $15-\mathrm{mL}$ pressure flask. The mixture was heated at $150^{\circ} \mathrm{C}$ for $72 \mathrm{~h}$, after which the resulted yellow solid was collected and purified through a standard workup to obtain the target $\mathrm{COF}$ g- $\mathrm{C}_{40} \mathrm{~N}_{3}$-COF with nearly quantitative yield (see details in the methods section). In order for comparison, a model compound 3,5-dicyano-2,4,6-tristyrylpyridine (denoted as DCTSP) was also synthesized by a reaction of DCTMP and benzaldehyde under the same reaction condition.

Characterizations of $\mathbf{g}-\mathrm{C}_{\mathbf{x}} \mathrm{N}_{\mathbf{y}}-\mathrm{COFs}$. PXRD analyses revealed the crystallinity of the resulting COFs. In conjunction with structural simulation, the structural features of $\mathrm{g}-\mathrm{C}_{\mathrm{x}} \mathrm{N}_{\mathrm{y}}-\mathrm{COF}$ were elucidated. Of these, the obtained PXRD pattern of $\mathrm{g}-\mathrm{C}_{40} \mathrm{~N}_{3}$-COF was dominated by an intense reflection in the low-angle region at $2 \theta=2.62^{\circ}$, which was assigned to the (100) facet (Fig. 2b). Four other peaks at $4.53^{\circ}, 5.23^{\circ}, 6.94^{\circ}$, and $26.67^{\circ}$ were assigned to the (110), (200), (210), and (001) facets, respectively (Supplementary Fig. 14). Fully eclipsed AA layer stacking and staggered $\mathrm{AB}$ layer stacking models were generated. Geometrical energy minimizations of the structural models were conducted using the Materials Studio software package and diffraction patterns were simulated. The experimental PXRD pattern agreed well with a pattern simulated from an AA-eclipsed layer stacking model with unit cell parameters $(a=37.419 \AA$, $b=$ $37.843 \AA, c=3.588 \AA$ and $\alpha=90.044^{\circ}, \beta=90.061^{\circ}, \gamma=119.756^{\circ}$ ) in the space group $P \overline{1}$. While, the staggered $\mathrm{AB}$ layer stacking model did not match the experimental pattern. Finally, Pawley refinement against experimental PXRD data provided good agreement factors $\left(R_{\mathrm{wp}}=3.47 \%\right.$ and $\left.R_{\mathrm{p}}=2.75 \%\right)$. In addition, the (100) peak had a small full-width at half-maximum value of $0.36^{\circ}$, which is comparable to those of imine-based COFs, indicating the high crystallinity of the framework. As contrast, g- $\mathrm{C}_{31} \mathrm{~N}_{3}-\mathrm{COF}$ and g- $\mathrm{C}_{37} \mathrm{~N}_{3}$-COF exhibited lower crystallinity, as demonstrated by their broadened diffraction peaks of (100) facets at $2 \theta=3.36^{\circ}$ and $5.61^{\circ}$. Simulated AA stacking modes matched better with their PXRD patterns, from which hexagonal pore diameters were estimated as $2.6 \mathrm{~nm}$ and $1.6 \mathrm{~nm}$ for $\mathrm{g}-\mathrm{C}_{31} \mathrm{~N}_{3}-\mathrm{COF}$ and $\mathrm{g}-\mathrm{C}_{37} \mathrm{~N}_{3}$-COF, respectively (Fig. 2c, d).

The permanent porosities of $g-\mathrm{C}_{\mathrm{x}} \mathrm{N}_{\mathrm{y}}$-COFs were investigated by nitrogen sorption analysis at $77 \mathrm{~K}$. As illustrated in Fig. 2e, f, the nitrogen sorption isotherms of g- $\mathrm{C}_{40} \mathrm{~N}_{3}$ - COF and $\mathrm{g}-\mathrm{C}_{31} \mathrm{~N}_{3^{-}}$ $\mathrm{COF}$ are assigned to type-IV reversible isotherms, indicative of their mesoporous characteristics. Whereas, g- $\mathrm{C}_{37} \mathrm{~N}_{3}-\mathrm{COF}$ shows type-I reversible isotherm, suggesting its microporous structure (Fig. 2g). The Brunauer-Emmett-Teller (BET) surface areas of g$\mathrm{C}_{40} \mathrm{~N}_{3}-\mathrm{COF}, \mathrm{g}-\mathrm{C}_{31} \mathrm{~N}_{3}-\mathrm{COF}$, and g- $\mathrm{C}_{37} \mathrm{~N}_{3}$-COF were calculated to be $1235 \mathrm{~m}^{2} \mathrm{~g}^{-1}, 864 \mathrm{~m}^{2} \mathrm{~g}^{-1}$, and $1012 \mathrm{~m}^{2} \mathrm{~g}^{-1}$, respectively, which were much higher than those for the other $\mathrm{C}=\mathrm{C}$ linked COFs reported to date (Fig. 1a) ${ }^{8,10}$. The pore size distribution (PSD) was evaluated with non-local density functional theory (NLDFT). The PSDs of $g-\mathrm{C}_{\mathrm{x}} \mathrm{N}_{\mathrm{y}}$-COFs exhibited maxima of $3.2 \mathrm{~nm}, 2.43 \mathrm{~nm}$, and $1.57 \mathrm{~nm}$, which were highly in line with the predicted values for AA eclipsed geometries of the frameworks.

The defined chemical structures of $g-\mathrm{C}_{\mathrm{x}} \mathrm{N}_{\mathrm{y}}$-COFs were confirmed through ${ }^{13} \mathrm{C}$ cross-polarization/magic angle spinning solid-state nuclear magnetic resonance (CP/MAS ssNMR) spectroscopy, Fourier transform infrared (FT-IR) spectroscopy, thermogravimetric analysis (TGA), and elemental analysis. As an example, ${ }^{13} \mathrm{C}$ ssNMR spectra of $\mathrm{g}-\mathrm{C}_{40} \mathrm{~N}_{3}-\mathrm{COF}$ and ${ }^{13} \mathrm{C} \mathrm{NMR}$ spectra of the model compound DCTSP in $\mathrm{CDCl}_{3}$ were combined in Fig. 3a. The peak at $117 \mathrm{ppm}$ was assigned to the carbon atoms in cyano groups (a). The carbon atoms on pyridine unit (b, c, and d) corresponded to the peaks at 103,159 , and $155 \mathrm{ppm}$, respectively. The signals of vinyl carbon atoms (e, f, h and i) were found at 119, 120, 135, and $136 \mathrm{ppm}$, respectively. The intense resonance at $127 \mathrm{ppm}$ was ascribed to the hydrogen-bonded aromatic carbons (g). The peak at $140 \mathrm{ppm}$ was attributed to the carbon-attached aromatic carbons (j). FT-IR spectra (Fig. 3b) revealed that the stretching vibration peak of the cyano group $(\mathrm{CN})$ was located at approximately 2225 $\mathrm{cm}^{-1}$, which was also observed for the monomer DCTMP. Moreover, a peak which was observed at $1690 \mathrm{~cm}^{-1}$ attributed to the $\mathrm{C}=\mathrm{O}$ stretching vibration of the monomer DFPTP, disappeared in $\mathrm{g}_{-} \mathrm{C}_{40} \mathrm{~N}_{3}-\mathrm{COF}$, indicating a high polymerization degree. Notably, in addition to the peak at $1621 \mathrm{~cm}^{-1}$, which was attributable to the $\mathrm{C}=\mathrm{C}$ moiety, the peak at $970 \mathrm{~cm}^{-1}$ engendered by the trans- $\mathrm{HC}=\mathrm{CH}$ stretch vibration clearly manifested the trans-configurations of disubstituted olefin linkages in the entire framework. TGA revealed the extremely high thermal stability of g$\mathrm{C}_{40} \mathrm{~N}_{3}$-COF in $\mathrm{N}_{2}$ up to $500{ }^{\circ} \mathrm{C}$, with the framework exhibiting less than $10 \%$ weight loss (Supplementary Fig. 6). Elemental analysis showed that the elemental contents (C: $84.68 \%, \mathrm{~N}: 8.38 \%$ and $\mathrm{H}$ : $4.95 \%$ ) were close to the theoretical data (C: $87.89 \%, \mathrm{~N}: 7.69 \%$, and $\mathrm{H}: \quad 4.43 \%$ ). X-ray photoelectron spectroscopy (XPS) further provided detailed information regarding the chemical structure of the framework (Supplementary Fig. 4). In high-resolution spectra, the $\mathrm{C} 1 s$ peak at $284.5 \mathrm{eV}$ and the $\mathrm{N} 1 s$ peak at $399.0 \mathrm{eV}$ were assigned to the $s p$ hybrid $\mathrm{C} \equiv \mathrm{N}$ moiety in cyano group. The peaks at 286.3 and $285.0 \mathrm{eV}$ in the $\mathrm{C} 1 s$ zone were attributed to electrons originating from $s p^{2}$ carbon atoms in vinyl groups and aromatic rings, respectively. The peak at $399.5 \mathrm{eV}$ in the $\mathrm{N} 1 s$ zone was ascribed to pyridine nitrogen atoms. Similarly, the structural 
a

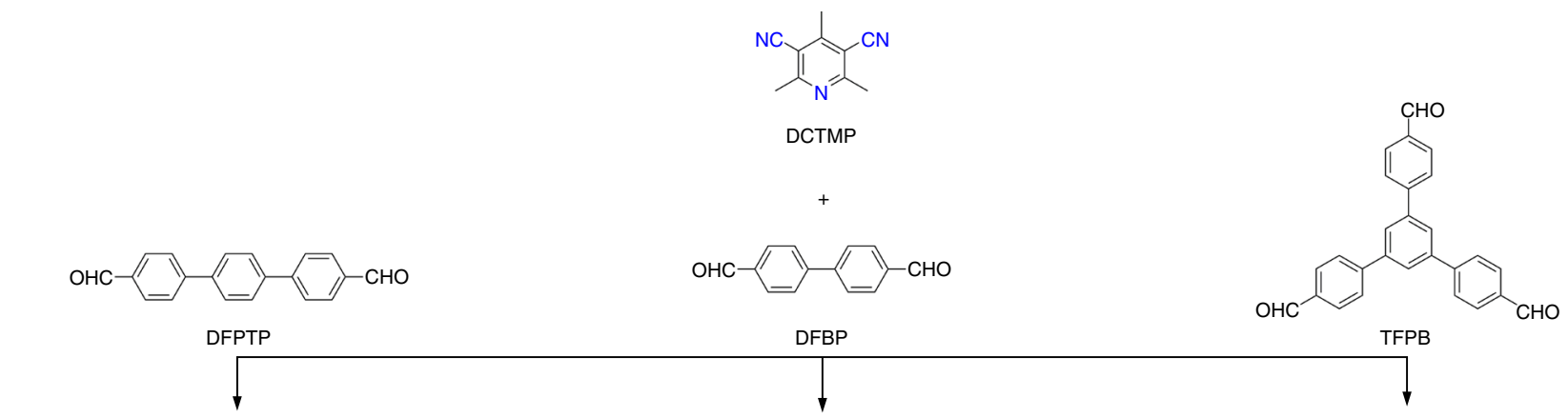

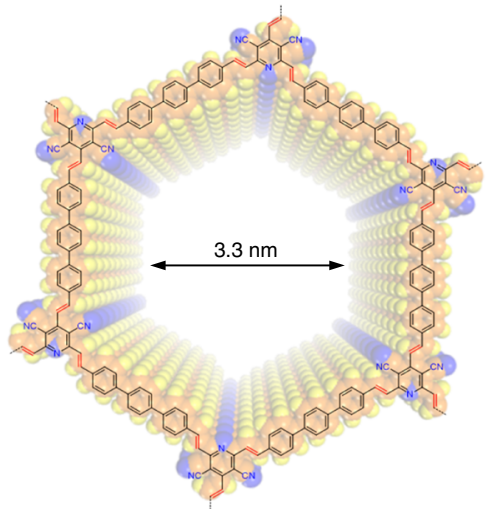

g- $\mathrm{C}_{40} \mathrm{~N}_{3}-\mathrm{COF}$

b
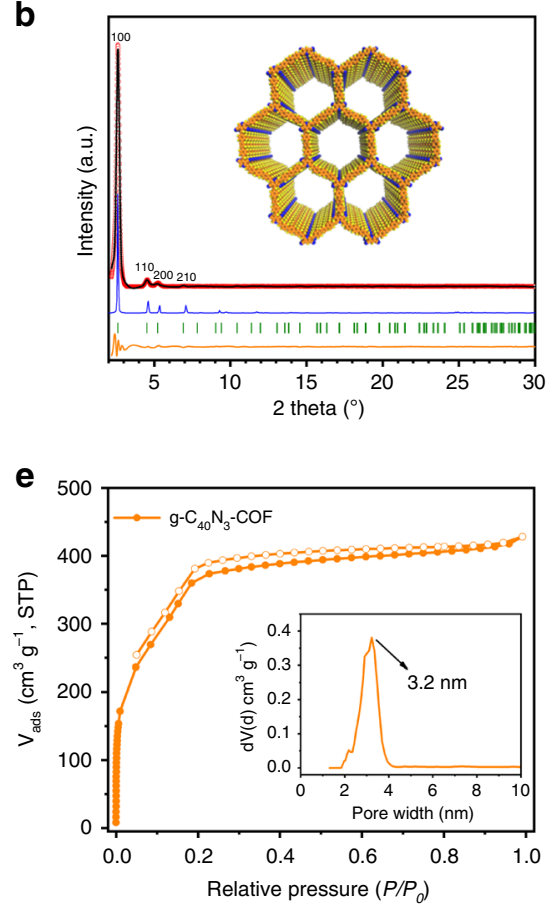

C
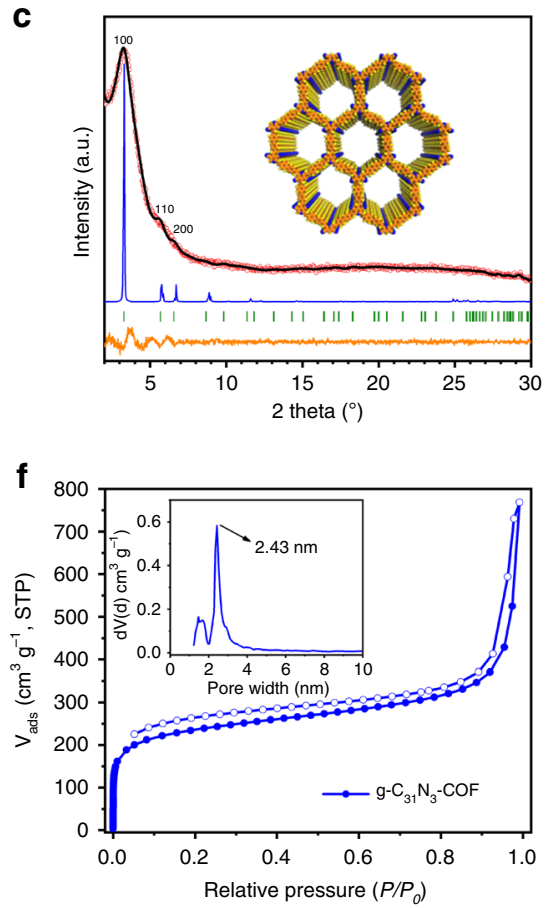

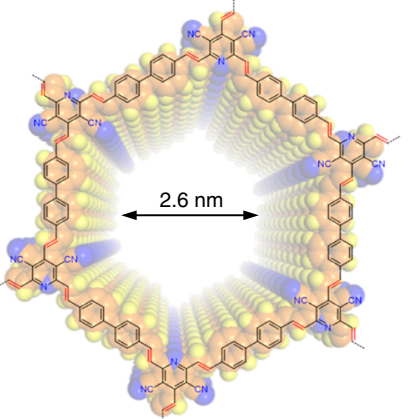

g- $\mathrm{C}_{31} \mathrm{~N}_{3}-\mathrm{COF}$

d

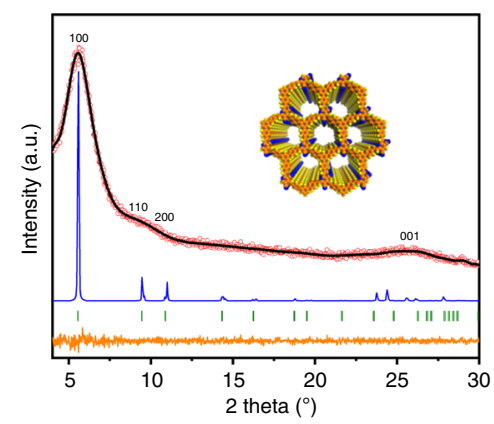

g

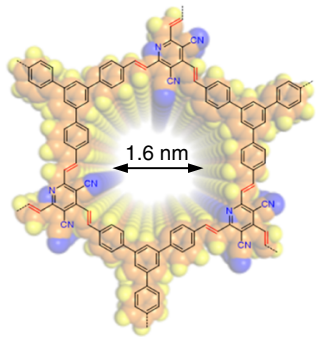

$\mathrm{g}-\mathrm{C}_{37} \mathrm{~N}_{3}-\mathrm{COF}$

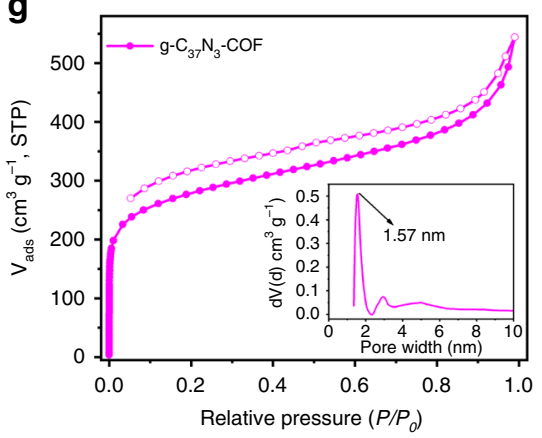

Fig. 2 Characterizations of crystal and porous structures for $g-C_{x} N_{y}-C O F s$. a Illustration of synthetic procedures of g- $C_{x} N_{y}-C O F s$. b, c and $\mathbf{d}$ PXRD patterns for $\mathrm{g}-\mathrm{C}_{40} \mathrm{~N}_{3}-\mathrm{COF}, \mathrm{g}-\mathrm{C}_{31} \mathrm{~N}_{3}-\mathrm{COF}$, and g- $\mathrm{C}_{37} \mathrm{~N}_{3}$-COF: comparison between the experimental (red circle) and Pawley refined (black) profiles, the simulated patterns for eclipsed AA stacking mode (blue), the Bragg positions (green) and the refinement differences (orange). Insets: the crystal structures of corresponding g- $\mathrm{C}_{x} \mathrm{~N}_{y}$-COFs assuming the eclipsed stacking viewed along [001] directions. $\mathbf{e}, \mathbf{f}$ and $\mathbf{g}$ Nitrogen adsorption and desorption isotherms of g- $\mathrm{C}_{40} \mathrm{~N}_{3}-\mathrm{COF}, \mathrm{g}-\mathrm{C}_{31} \mathrm{~N}_{3}-\mathrm{COF}$, and g- $\mathrm{C}_{37} \mathrm{~N}_{3}-\mathrm{COF}$. Insets: the pore size distributions calculated from non-local density functional theory

characterizations of $\mathrm{g}-\mathrm{C}_{31} \mathrm{~N}_{3}-\mathrm{COF}$ and $\mathrm{g}-\mathrm{C}_{37} \mathrm{~N}_{3}-\mathrm{COF}$ were also systematically performed for the verification of their chemical structures (Supplementary Figs. 1-6).

HRTEM was used to further confirm the formation of a periodic porous framework for $\mathrm{g}-\mathrm{C}_{40} \mathrm{~N}_{3}$-COF. The lattice fringes are depicted in Fig. 4a, revealing an ordered alignment with a high degree of crystallinity. A honeycomb-like porous structure was clearly visualized along the [001] plane under high resolution (Fig. 4b). As indicated by a fast Fourier transform (inset in Fig. 4a) conducted on a selected area (red square in Fig. 4a), a hexagonal 
a

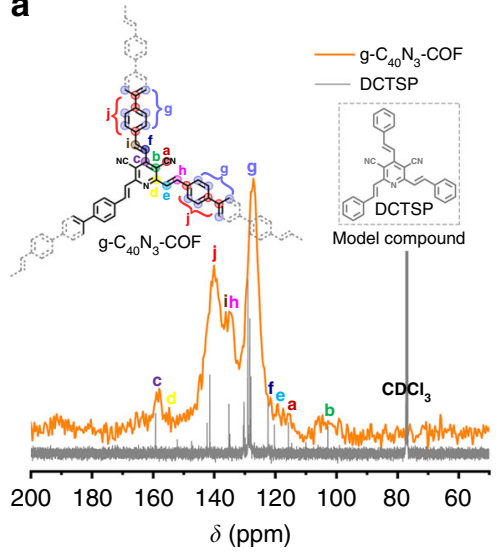

b

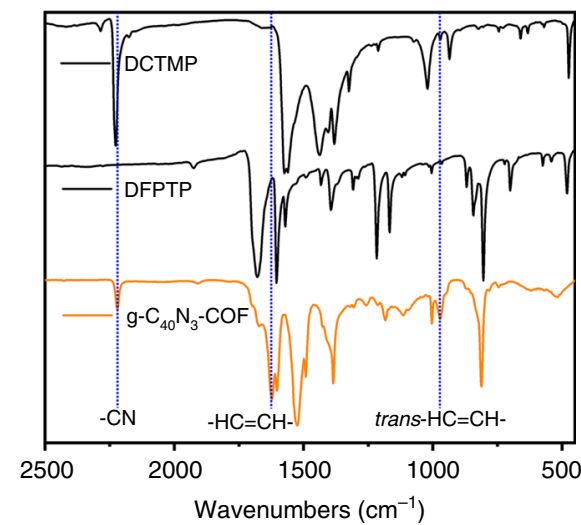

Fig. 3 Characterizations of chemical structures for g- $\mathrm{C}_{40} \mathrm{~N}_{3}$-COF. a ${ }^{13} \mathrm{C} C P / M A S$ solid-state NMR spectra of g-C ${ }_{40} \mathrm{~N}_{3}-\mathrm{COF}$, compared with ${ }^{13} \mathrm{C}$ NMR spectra of DCTSP (model compound) in $\mathrm{CDCl}_{3}$. b FT-IR spectra of $\mathrm{g}-\mathrm{C}_{40} \mathrm{~N}_{3}$-COF and corresponding monomers
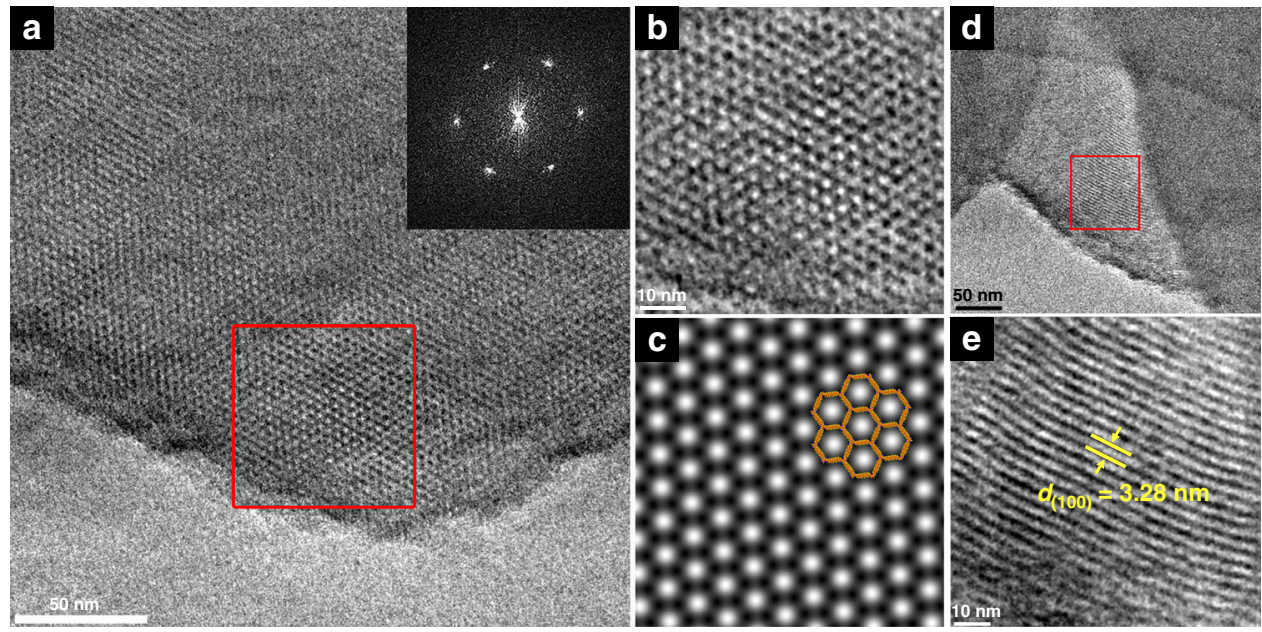

Fig. 4 TEM characterization of $g-\mathrm{C}_{40} \mathrm{~N}_{3}$-COF. a TEM image of $\mathrm{g}-\mathrm{C}_{40} \mathrm{~N}_{3}$-COF. Inset: fast Fourier transform (FFT) from the red square marked area. b highresolution TEM image of $\mathrm{g}-\mathrm{C}_{40} \mathrm{~N}_{3}$-COF showing hexagonal pores viewing from [001] direction. c Simulated HRTEM image. The eclipsed structure model of g- $\mathrm{C}_{40} \mathrm{~N}_{3}-\mathrm{COF}$ is overlaid. d TEM image of g- $\mathrm{C}_{40} \mathrm{~N}_{3}-\mathrm{COF}$ from different areas. e Enlarged HRTEM image of red square marked area in d, showing $1 \mathrm{D}$ channels viewing from [110] direction with the pore channel diameter determined as $3.28 \mathrm{~nm}$

arrangement of six white diffraction spots was found in the raw HRTEM image, corresponding to (100) facet. An observation from the [110] direction (Fig. 4d) revealed the distinct onedimensional channels with a uniform diameter of $\sim 3.28 \mathrm{~nm}$ (Fig. 4e), which is consistent with the pore diameter of $3.3 \mathrm{~nm}$ in the simulated COF structure, according to PXRD analysis. In most cases of COFs, limited HRTEM images were achieved, primarily because skeletal structures could be easily damaged under high-energy electron beams. Recently, a low-dose TEM technique was developed for realizing well-resolved images of COFs with electron beam-sensitive linkages (e.g., imine bonds) ${ }^{31}$. By contrast, g- $\mathrm{C}_{40} \mathrm{~N}_{3}$-COF could be clearly visualized even under normal TEM measurement conditions without any additional techniques. This phenomenon strongly supports the robust network of the as-synthesized $\mathrm{COF}$ through $\mathrm{C}=\mathrm{C}$ linkages. Clear observation of ordered domains in the TEM images of $\mathrm{g}$ $\mathrm{C}_{31} \mathrm{~N}_{3}$ - $\mathrm{COF}$ and g- $\mathrm{C}_{37} \mathrm{~N}_{3}$ - $\mathrm{COF}$ was difficult, likely due to their lower crystallinity than $\mathrm{g}^{-} \mathrm{C}_{40} \mathrm{~N}_{3}$ - $\mathrm{COF}$ (Supplementary Fig. 17).

Optical and electronic properties. The electronic properties of these $\mathrm{g}-\mathrm{C}_{\mathrm{x}} \mathrm{N}_{\mathrm{y}}$-COFs were systematically investigated by photophysical and electrochemical measurements. We took the high crystalline COF g- $\mathrm{C}_{40} \mathrm{~N}_{3}$-COF as an example for detailed elucidation. Its ultraviolet/visible diffuse reflectance spectroscopy (UV/vis DRS) showed a broad absorption band covering both UV and visible-light regions, with absorption edge at $550 \mathrm{~nm}$ (Fig. 5a). The absorption maxima at $500 \mathrm{~nm}$ for $\mathrm{g}-\mathrm{C}_{40} \mathrm{~N}_{3}-\mathrm{COF}$ was observed, which was red-shifted over $150 \mathrm{~nm}$ in comparison with that of $350 \mathrm{~nm}$ for DCTSP (model compound), indicating that the $2 \mathrm{D}$ network in the former case possesses extended $\pi$-conjugated structure. $\mathrm{g}-\mathrm{C}_{40} \mathrm{~N}_{3}$-COF with the longest polyphenylene spacer showed a redshift of the absorption edge in its DRS as compared to the other two COFs $\mathrm{g}_{-} \mathrm{C}_{31} \mathrm{~N}_{3}$-COF and g- $\mathrm{C}_{37} \mathrm{~N}_{3}-\mathrm{COF}$, suggesting its stronger light harvesting ability in the visible region (Supplementary Fig. 7). Accordingly, the optical band gaps of $\mathrm{g}-\mathrm{C}_{\mathrm{x}} \mathrm{N}_{\mathrm{y}}$-COFs were determined from the KubelkaMunk (K-M) function. An optical band gap of $2.36 \mathrm{eV}$ was determined for $\mathrm{g}_{-} \mathrm{C}_{40} \mathrm{~N}_{3}$-COF (Fig. 5b), which was smaller than that of $\mathrm{g}-\mathrm{C}_{31} \mathrm{~N}_{3}-\mathrm{COF}(2.40 \mathrm{eV})$ and $\mathrm{g}-\mathrm{C}_{37} \mathrm{~N}_{3}-\mathrm{COF}(2.52 \mathrm{eV})$. Upon irradiation at $365 \mathrm{~nm}$ by UV lamp, the solid powder sample of g- $\mathrm{C}_{40} \mathrm{~N}_{3}$-COF emitted strong orange-yellow fluorescence, its fluorescence spectra showed an emission maximum at $563 \mathrm{~nm}$ (Fig. 5a). This phenomenon was presumably attributed to that the chromophores fixed in the rigid framework can efficiently get rid of aggregate-caused emission quenching ${ }^{32}$. Similar fluorescent 

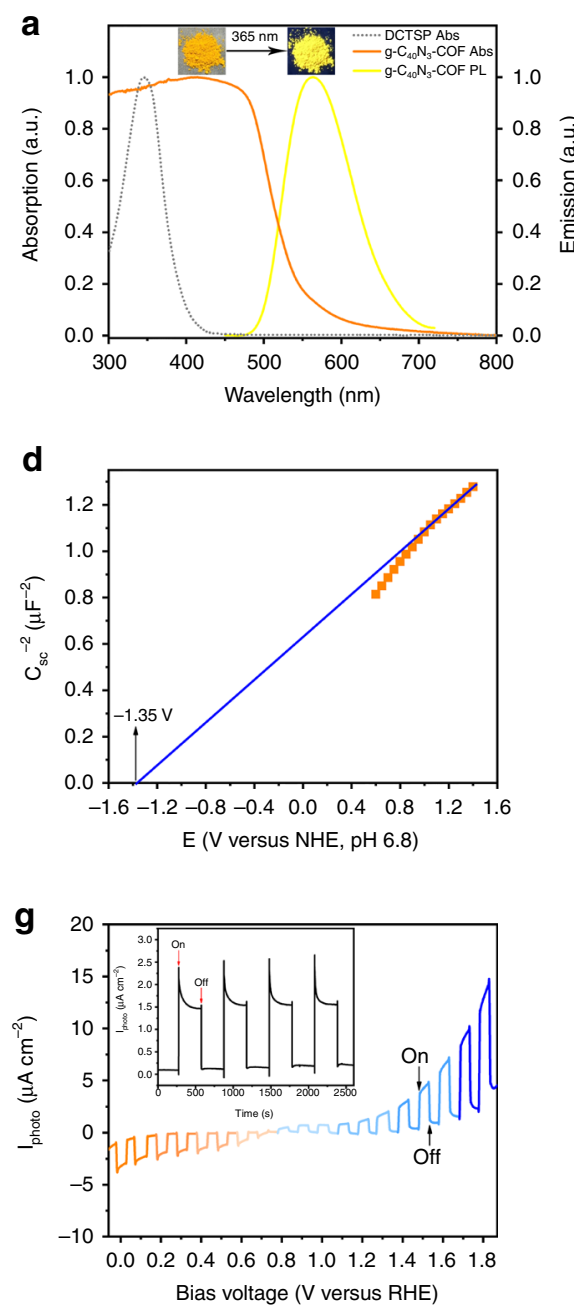
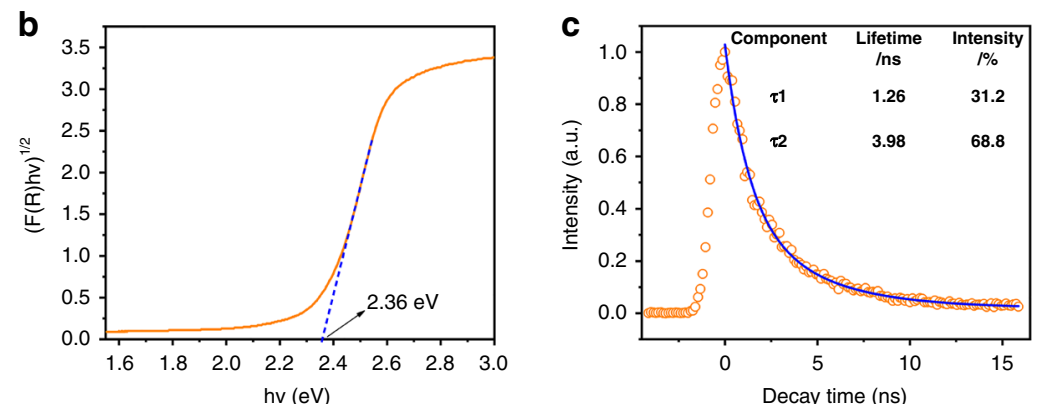

e
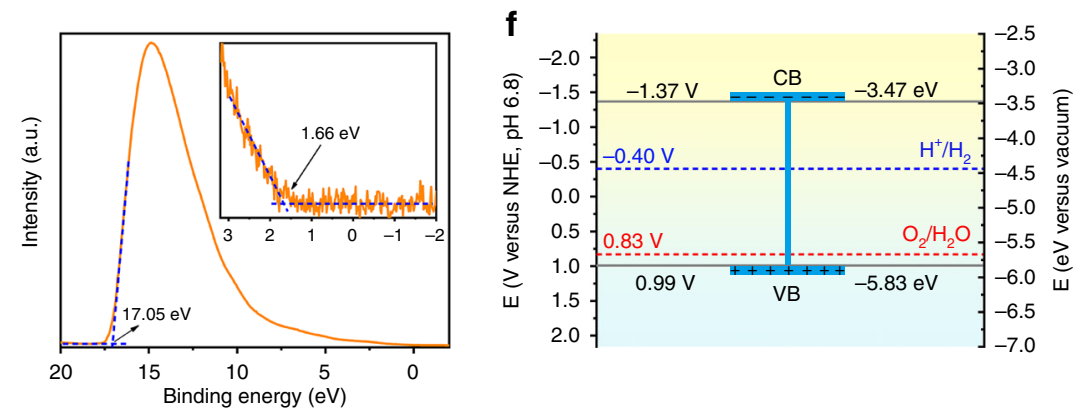

h
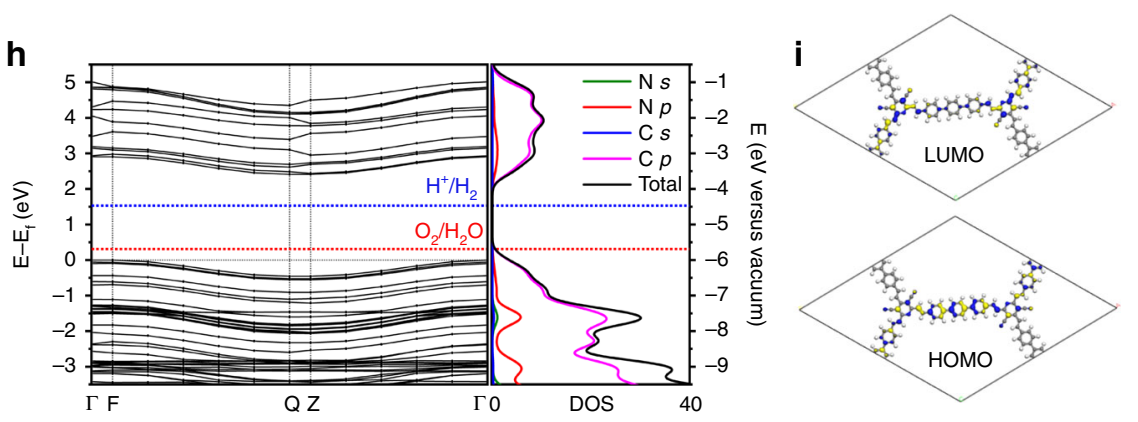

Fig. 5 Optical and electronic properties of g- $\mathrm{C}_{40} \mathrm{~N}_{3}-\mathrm{COF}$. a UV/vis diffuse reflectance spectra (DRS) and steady-state photoluminescence (PL) spectra of g- $\mathrm{C}_{40} \mathrm{~N}_{3}$-COF. The gray dash line represents solution UV/vis absorption spectra of DCTSP (model compound) recorded in dichloromethane. The upper inset shows the digital photograph of the sample under ambient light and $365 \mathrm{~nm}$ UV-lamp. b Band gap determined from the Kubelka-Munk-transformed reflectance spectra. c PL decay spectra monitored at $563 \mathrm{~nm}$ under $365 \mathrm{~nm}$ excitation at $298 \mathrm{~K}$. d Mott-Schottky (M-S) plot for g- $\mathrm{C}_{40} \mathrm{~N}_{3}-\mathrm{COF}$ measured in $0.2 \mathrm{M} \mathrm{Na} 2 \mathrm{SO}_{4}$ $\left(\mathrm{pH}\right.$ 6.8) with $\mathrm{Ag} / \mathrm{AgCl}\left(+0.199 \mathrm{~V}\right.$ vs. NHE) as the reference electrode in dark. e UPS spectrum of $\mathrm{g}-\mathrm{C}_{40} \mathrm{~N}_{3}-\mathrm{COF}$. $\mathbf{f}$ Band positions of g-C $\mathrm{C}_{40} \mathrm{~N}_{3}-\mathrm{COF}$ ( $\mathrm{These}$ vacuum level values were converted to electrochemical potentials according to: $-4.44 \mathrm{eV}$ vs. vacuum level is equal to $-0.4 \mathrm{~V}$ vs. $\mathrm{NHE}$ at $\mathrm{pH} 6.8$ ). $\mathbf{g}$ Chopped current-potential (I-V) curve of $\mathrm{g}-\mathrm{C}_{40} \mathrm{~N}_{3}$-COF photoelectrode under visible light (300 W Xenon light with cut-off filter $\lambda>420 \mathrm{~nm}$ ). Electrolyte: Ar-saturated $0.2 \mathrm{M} \mathrm{Na}_{2} \mathrm{SO}_{4}$ aqueous solution. The applied potential was swept at $+10 \mathrm{mV} \mathrm{s}^{-1}$ under intermittent irradiation with a period of $5 \mathrm{~s}$. Inset is chopped anodic photocurrent density vs. time recorded on a g- $\mathrm{C}_{40} \mathrm{~N}_{3}-\mathrm{COF}$ photoanode at $1.0 \mathrm{~V}$ vs. RHE. $\mathbf{h}$ Electronic properties of g- $\mathrm{C}_{40} \mathrm{~N}_{3}-\mathrm{COF}$ using DFT calculations and corresponding density of states (DOS). $\mathbf{i}$ The Kohn-Sham orbitals of $\mathrm{HOMO}$ and LUMO of $\mathrm{g}-\mathrm{C}_{40} \mathrm{~N}_{3}-\mathrm{COF}$. C gray, $\mathrm{N}$ blue, $\mathrm{H}$ white

characters were also found for $\mathrm{g}-\mathrm{C}_{31} \mathrm{~N}_{3}$-COF and g- $\mathrm{C}_{37} \mathrm{~N}_{3}$-COF (Supplementary Fig. 8a). Time-resolved fluorescence decay spectroscopy was performed to evaluate the extent of exciton recombination, and which provided information about the average lifetime of photo-excited electrons. The fluorescence decay curves of all three COFs fitted the lifetimes with two exponential components (Fig. $5 \mathrm{c}$ and Supplementary Fig. 8b), and the average lifetimes of $\mathrm{g}-\mathrm{C}_{40} \mathrm{~N}_{3}-\mathrm{COF}, \mathrm{g}-\mathrm{C}_{31} \mathrm{~N}_{3}-\mathrm{COF}$, and g$\mathrm{C}_{37} \mathrm{~N}_{3}-\mathrm{COF}$ were estimated to be $3.31,2.71$, and $2.58 \mathrm{~ns}$, respectively. The longest fluorescence lifetime of g- $\mathrm{C}_{40} \mathrm{~N}_{3}$-COF suggests its extended $\pi$-conjugated structure, favorable for charge isolation. To further study the electronic structure of g- $\mathrm{C}_{40} \mathrm{~N}_{3^{-}}$ COF, Mott-Schottky (M-S) measurement was conducted to estimate its relative band positions. The positive slope indicates typical n-type semiconductor characteristic for $\mathrm{g}^{-} \mathrm{C}_{40} \mathrm{~N}_{3}$-COF (Fig. 5d). The flat-band potential $\left(\mathrm{E}_{\mathrm{fb}}\right)$ of $\mathrm{g}-\mathrm{C}_{40} \mathrm{~N}_{3}-\mathrm{COF}$ was fitted to be $-1.35 \mathrm{~V}$ vs. normal hydrogen electrode (NHE) at $\mathrm{pH} 6.8$ from the $x$ intercept of the liners region of M-S plots. Moreover, ultraviolet photoelectron spectroscopy (UPS) was used to determine the energy level of valence band maximum $\left(\mathrm{E}_{\mathrm{VB}}\right)$. The $\mathrm{E}_{\mathrm{VB}}$ of $-5.83 \mathrm{eV}$ (vs. vacuum level) was calculated by subtracting the UPS width from excitation energy (He I, $21.22 \mathrm{eV}$ ) (Fig. 5e). Combined with the aforementioned optical band gap, the conduction band minimum $\left(\mathrm{E}_{\mathrm{CB}}\right)$ could be calculated as $-3.47 \mathrm{eV}$ vs. vacuum level (i.e., $-1.37 \mathrm{~V}$ vs. NHE at $\mathrm{pH} 6.8$ ) (Fig. $5 \mathrm{f}^{33}$, which is quite similar to the above flat-band potential. For comparison, all data for these COFs were collected in Table 1. In addition, we performed density-functional-theory (DFT) calculations to theoretically confirm the electronic structures of g- $\mathrm{C}_{40} \mathrm{~N}_{3}$-COF. The band structures with an ideal infinite model along the high symmetry line from the $k$-points in the first Brillouin zone were demonstrated in Fig. 5h, suggesting an indirect band gap of 2.292 $\mathrm{eV}$, which was in agreement with experimental value $(2.36 \mathrm{eV})$. The partial density of states (PDOS), as well as the wave functions 
Table 1 Electronic properties of $\mathrm{g}-\mathrm{C}_{\mathrm{x}} \mathrm{N}_{\mathrm{y}}-\mathrm{COFs}$

\begin{tabular}{|c|c|c|c|c|c|c|c|c|}
\hline Samples & $\lambda_{\mathrm{abs}}{ }^{\mathrm{a}}(\mathrm{nm})$ & $\begin{array}{l}\text { Optical } \\
\text { gapb (eV) }^{\text {b }}\end{array}$ & $\lambda_{\mathrm{em}}^{\mathrm{c}}(\mathrm{nm})$ & $\tau_{\text {avg }}^{d}(n s)$ & $\begin{array}{l}\text { Quantum } \\
\text { yield (\%) }\end{array}$ & $E_{f b} e(V)$ & $E_{V_{B}}^{f}(e V)$ & $E_{C B}^{f}(e V)$ \\
\hline $\mathrm{g}-\mathrm{C}_{40} \mathrm{~N}_{3}-\mathrm{COF}$ & 550 & 2.36 & 563 & 3.31 & 0.7 & -1.35 & -5.83 & -3.47 \\
\hline $\mathrm{g}-\mathrm{C}_{31} \mathrm{~N}_{3}-\mathrm{COF}$ & 560 & 2.40 & 572 & 2.71 & 2.0 & -0.94 & -6.31 & -3.91 \\
\hline $\mathrm{g}-\mathrm{C}_{37} \mathrm{~N}_{3}-\mathrm{COF}$ & 525 & 2.52 & 570 & 2.58 & 3.2 & -1.78 & -5.54 & -3.02 \\
\hline \multicolumn{9}{|c|}{$\begin{array}{l}\text { aUV-vis absorption edge } \\
\text { bDetermined from the Kubelka-Munk-transformed reflectance spectra } \\
\text { cFluorescence emission upon excitation at } 365 \mathrm{~nm} \\
\text { dAverage fluorescence lifetime recorded upon excitation at } \lambda_{\text {exc }}=365 \mathrm{~nm} \text { with a laser and observed at } \lambda_{\text {em }}=563,572 \text {, and } 570 \mathrm{~nm} \text { for g-C } \mathrm{C}_{40} \mathrm{~N}_{3}-\mathrm{COF}, g-\mathrm{C}_{31} \mathrm{~N}_{3}-\mathrm{COF} \text {, and g-C } \mathrm{C}_{37} \mathrm{~N}_{3}-\mathrm{COF} \text {, respectively } \\
\text { eThe flat-band potentials obtained from Mott-Schottky measurement are with respect to NHE at pH } 6.8 \\
\text { fThese values determined from UPS and optical gap are with respect to vacuum level }\end{array}$} \\
\hline
\end{tabular}

of both conduction band minimum (CBM) and valence band maximum (VBM) was analyzed as shown in Fig. 5h, which clearly revealed that the top of VBM and the bottom of CBM were mainly contributed by the $2 p$ orbital of $\mathrm{C}$ atoms. Such results suggest that the intrinsic electronic properties of the as-prepared $\mathrm{COF}$ are arising from the well $\pi$-delocalization over the carbonrich $2 \mathrm{D}$ skeleton (Fig. $5 \mathrm{i}$ ). In order to evaluate the photoelectric responses of these COFs, we performed photocurrent tests by using their film electrodes on indium-tin oxide (ITO) substrates in a solution of $0.2 \mathrm{M} \mathrm{Na}_{2} \mathrm{SO}_{4}(\mathrm{pH} 6.8)$. The chopped currentpotential (I-V) curve of $\mathrm{g}-\mathrm{C}_{40} \mathrm{~N}_{3}$-COF photoelectrode is shown in Fig. $5 \mathrm{~g}$, revealing the remarkable photoresponses towards light on/off switching. A cathodic photocurrent was observed at the potentials below $0.8 \mathrm{~V}$ vs. RHE, and showing a saturated current density value of ca. $2.5 \mu \mathrm{A} \mathrm{cm}^{-2}$ below $0.4 \mathrm{~V}$ vs. RHE. Meanwhile, at bias voltage above $0.8 \mathrm{~V}$ vs. RHE, an increased anodic photocurrent was found, reaching ca. $10 \mu \mathrm{A} \mathrm{cm}^{-2}$ at $1.8 \mathrm{~V}$ vs. RHE. Such an ambipolar photoconduction mode for $\mathrm{g}^{-} \mathrm{C}_{40} \mathrm{~N}_{3}$-COF manifests its capability of the generation and migration of either electrons or holes upon light irradiation with respect to its preferable band structure for overall water splitting. The similar phenomenon was also observed in a few polymeric photocatalysts (e.g., g- $\left.\mathrm{C}_{3} \mathrm{~N}_{4}\right)^{34}$. In addition, we tested long-time photocurrent response for $\mathrm{g}_{-} \mathrm{C}_{40} \mathrm{~N}_{3}-\mathrm{COF}$ at an applied bias of $1.0 \mathrm{~V}$ vs. RHE, apparent anodic photocurrent was also detected upon the chopped irradiation via light on/off switching (Fig. $5 \mathrm{~g}$ inset). The photocurrent density of g- $\mathrm{C}_{40} \mathrm{~N}_{3}$-COF was nearly constant within the mearsurement period of $2600 \mathrm{~s}$, indicating its excellent stability under light irradiation ${ }^{35}$. The photophysical properties and electrochemical behaviors of $\mathrm{g}-\mathrm{C}_{40} \mathrm{~N}_{3}$-COF encouraged us to further explore its application on photocatalytic water splitting. As mentioned, its band gap is sufficiently large to overcome the theoretical endothermic characteristic in water-splitting processes $(1.23 \mathrm{eV})$. In addition, the energy level for the reduction of $\mathrm{H}_{2} \mathrm{O}$ to $\mathrm{H}_{2}$ was observed to be below the $\mathrm{E}_{\mathrm{CB}}$ of $\mathrm{g}-\mathrm{C}_{40} \mathrm{~N}_{3}-\mathrm{COF}$, and the energy level for the oxidation of $\mathrm{H}_{2} \mathrm{O}$ to $\mathrm{O}_{2}$ was slightly above the $\mathrm{E}_{\mathrm{VB}}$ of $\mathrm{g}-\mathrm{C}_{40} \mathrm{~N}_{3}$-COF. The predicted CBM and VBM with respect to the LUMO and HOMO energy levels are well positioned for overall water-splitting. Therefore, the appropriate positions of the energy band structures for this type of COF permit the efficient transfer of photogenerated electrons and holes, respectively, and theoretically make it a promising photocatalyst for overall water splitting.

Photocatalytic properties. $\mathrm{H}_{2}$ evolution experiments were performed by irradiating a suspension of $50 \mathrm{mg}$ of $\mathrm{COF}$ in an aqueous solution containing sacrificial agent with visible light $(\lambda>420 \mathrm{~nm})$ at $12{ }^{\circ} \mathrm{C}$. After optimization of reaction conditions (Supplementary Figs. 34-36), 10 Vol\% of triethanolamine TEoA ( $\mathrm{pH}$ 10.30) was chose as sacrificial electron donor. Notably, in the absence of any cocatalyst (e.g., platinum), a bare sample of g- $\mathrm{C}_{40} \mathrm{~N}_{3}$-COF enabled steady production of hydrogen with an average $\mathrm{H}_{2}$ production rate of $2.9 \mu \mathrm{mol} \mathrm{h}^{-1}$ (Fig. 6a), which is comparable to the bulk g- $\mathrm{C}_{3} \mathrm{~N}_{4}$, but rarely observed for other metal-free polymeric materials. Such a $\mathrm{H}_{2}$ production rate is still relatively low, mostly attributed to the sluggish hydrogen elimination from a hydrogenated COF surface ${ }^{12}$. Hence, different amount of platinum (Pt) was in situ deposited into the network of COF by irradiation of the suspension containing certain equivalents of hexachloroplatinic acid and COF samples in water and TEoA mixture for $4 \mathrm{~h}$ under visible light. This modification (deposition of $\mathrm{Pt}$ ) enabled improving charge separation and facilitating proton reduction because of the lowest $\mathrm{H}_{2}$ absorption free energy for hydrogen release through the formation of Pt-H bonds. The correlation between the $\mathrm{H}_{2}$ production rate and the loading amount of $\mathrm{Pt}$ was systematically investigated. At the end of 4-hour in a series of tests, the average amount of hydrogen produced by $1,2,2.5,3,3.5$, and $5 \mathrm{wt} \%$ Pt-modified g- $\mathrm{C}_{40} \mathrm{~N}_{3}$-COF was $14.5,22.3,72.5,129.8,127.8$ and $112.6 \mu \mathrm{mol} \mathrm{h}^{-1}$, respectively (Supplementary Fig. 32). Thus, the $3 \mathrm{wt} \%$ Pt-modified g- $\mathrm{C}_{40} \mathrm{~N}_{3}-$ COF, which was the most active, was chosen for stability evaluation by running the reaction for a total of $28 \mathrm{~h}$ recorded in a 4 -h interval under visible-light irradiation $(\lambda>420 \mathrm{~nm})$ (Fig. 6b). The total amount of hydrogen evolved after $28 \mathrm{~h}$ was approximately 4400 $\mu \mathrm{mol}$, which far exceeded the hydrogen generation rates of most previously reported COF-based photocatalysts and confirmed that the primary hydrogen source was water rather than the decomposition products of the $\mathrm{COF}^{22}$. During the long-term photocatalytic test, we found that the $\mathrm{H}_{2}$ evolution amount per hour increased stepwise in the first $4 \mathrm{~h}$, after which it came to a plateau at an average $\mathrm{H}_{2}$ production rate of $153 \mu \mathrm{mol} \mathrm{h} \mathrm{h}^{-1}$. After $16 \mathrm{~h}$, the $\mathrm{H}_{2}$ evolution rate decreased slightly, probably due to the consumption of the sacrificial electron donor (i.e., TEoA). After adding another dose of TEoA, the highest $\mathrm{H}_{2}$ production rate of $206 \mu \mathrm{mol} \mathrm{h}^{-1}$ was achieved. The AQY is a crucial measure for evaluating the apparent efficiency of energy transformation from solar to hydrogen by photocatalysts, which is measured under monochromatic incident light. The AQY is calculated by dividing reactive electrons by the total incident photons and this value can be a standard for comparing the activities between different photocatalysts. In this study, the highest AQY obtained for $\mathrm{g}-\mathrm{C}_{40} \mathrm{~N}_{3}-\mathrm{COF}$ at $420 \mathrm{~nm}$ was $4.84 \%$ $( \pm 0.27 \%$ ), which remarkably exceeded the AQYs of most promising polymer-based photocatalysts reported so far, such as a trazinebased $\mathrm{N}_{3}-\mathrm{COF}\left(\mathrm{AQY}_{420 \mathrm{~nm}}=0.44 \%\right)^{22}$, a hydrazone-based TFPT$\mathrm{COF}\left(\mathrm{AQY}_{40 \mathrm{~nm}}=2.2 \%\right)^{21}$, an olefin-linked conjugated porous polymer OB-POP-3 $\left(\mathrm{AQY}_{420 \mathrm{~nm}}={ }^{\circ} 2.0 \%\right)$ in our previous work ${ }^{36}$, and sulfone-containing FS-COF $\left(\mathrm{AQY}_{420 \mathrm{~nm}}=3.2 \%\right)^{37}$. Moreover, the AQY recorded at $470,490,520$, and $578 \mathrm{~nm}$ was $4.47 \%$ $( \pm 0.27 \%), 3.90 \%( \pm 0.22 \%), 3.20 \%( \pm 0.27 \%)$, and $0.29 \%( \pm 0.01 \%)$, respectively (Fig. $6 \mathrm{c}$ ). This phenomenon clearly proves that the light conversion efficiency is highly dependent on the light-harvesting level within the covered energy regions for $\mathrm{g}_{-} \mathrm{C}_{40} \mathrm{~N}_{3}-\mathrm{COF}$. And the fact also indicates that the process of $\mathrm{H}_{2}$ generation is indeed driven by the absorption of light. We characterized the molecular structure of g- $\mathrm{C}_{40} \mathrm{~N}_{3}$-COF after long-term photocatalytic hydrogen evolution 
a

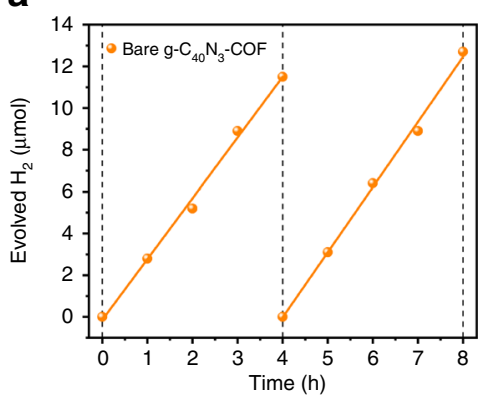

C

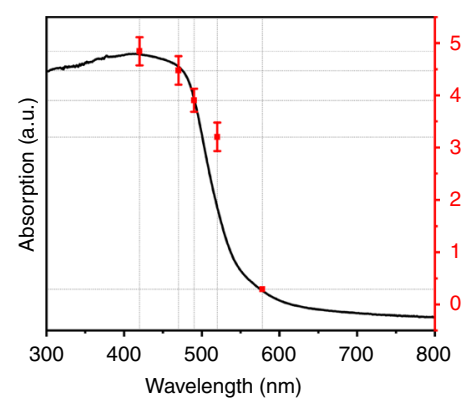

b

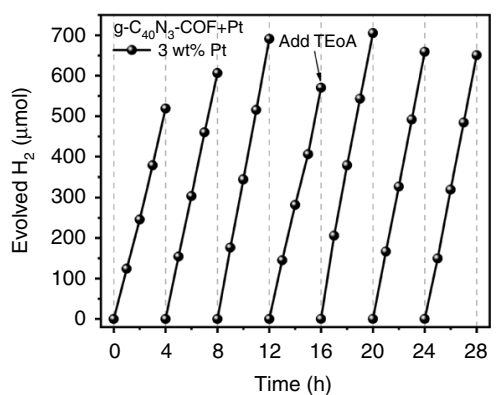

d

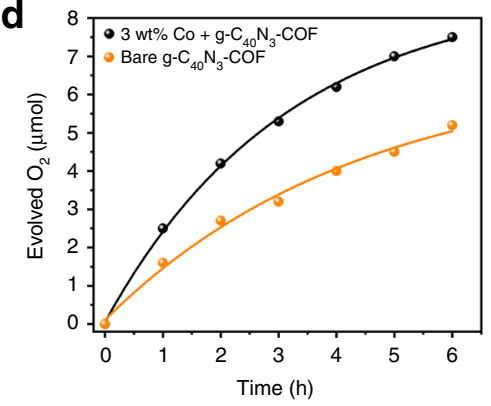

e

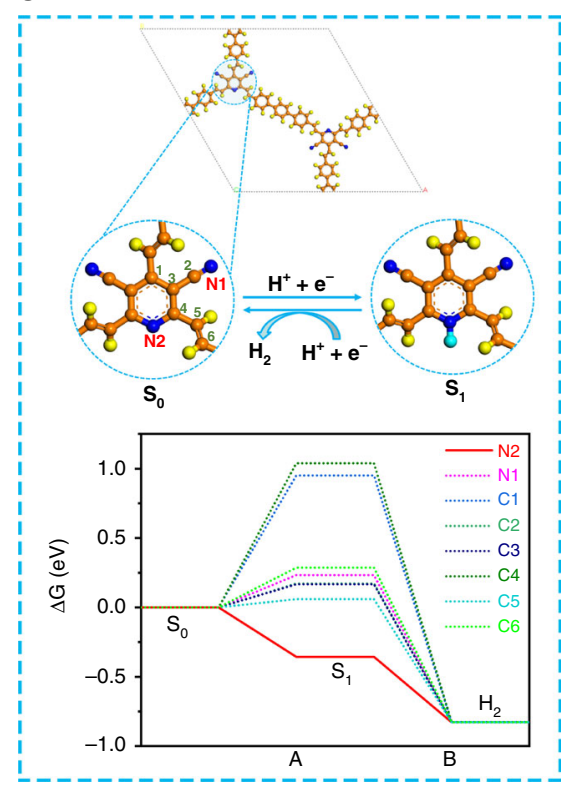

Fig. 6 Photocatalytic hydrogen evolution, oxygen evolution, and AQYs of $\mathrm{g}-\mathrm{C}_{40} \mathrm{~N}_{3}-\mathrm{COF}$. a Time course hydrogen evolution under visible light $(\lambda>420 \mathrm{~nm})$ irradiation from $\mathrm{H}_{2} \mathrm{O} / \mathrm{TEOA}\left(100 \mathrm{~mL} / 10 \mathrm{~mL}\right.$ ) mixture using $50 \mathrm{mg}$ bare (metal-free) $\mathrm{g}-\mathrm{C}_{40} \mathrm{~N}_{3}$-COF monitored over $8 \mathrm{~h}$ with evacuation every $4 \mathrm{~h}$ (dashed line). b Time course hydrogen evolution under visible light $\left(\lambda>420 \mathrm{~nm}\right.$ ) irradiation from $\mathrm{H}_{2} \mathrm{O} / \mathrm{TEOA}(100 \mathrm{~mL} / 10 \mathrm{~mL}) \mathrm{mixture}$ using $50 \mathrm{mg}$ of $3 \mathrm{wt} \% \mathrm{Pt}$ modified g- $\mathrm{C}_{40} \mathrm{~N}_{3}$-COF monitored over $28 \mathrm{~h}$ with evacuation every $4 \mathrm{~h}$ (dashed line). c Absorption spectrum and wavelength-specific apparent quantum yield ( $\mathrm{AQY}$ ) on $\mathrm{H}_{2}$ evolution measured with monochromatic LED light of wavelengths at 420,470,490, 520, and $578 \mathrm{~nm}$, respectively, using 50 mg of 3 wt\% Pt-modified g- $\mathrm{C}_{40} \mathrm{~N}_{3}-\mathrm{COF}$ in $\mathrm{H}_{2} \mathrm{O} / \mathrm{TE}$ OA $(100 \mathrm{~mL} / 10 \mathrm{~mL})$ mixture. $\mathbf{d}$ Time course oxygen evolution from water containing $0.01 \mathrm{M}$ silver nitrate as an electron acceptor under visible light $(\lambda>420 \mathrm{~nm})$ by $3.0 \mathrm{wt} \% \mathrm{Co}$-loaded and unmodified $\mathrm{g}-\mathrm{C}_{40} \mathrm{~N}_{3}-\mathrm{COF}$, respectively. $\mathrm{La}_{2} \mathrm{O}_{3}(0.2 \mathrm{~g})$ was used as a buffer. e Top: reaction cycles and active sites for $\mathrm{H}_{2}$ evolution from water ( $\mathrm{C}$ orange, $\mathrm{N}$ blue, $\mathrm{H}$ in COF: yellow, $\mathrm{H}$ from water: light blue). Bottom: free-energy variations for $\mathrm{H}_{2}$ evolution for each active site as labeled. The error bar represents the standard deviation from the repeated experiment after three times

test by solid-state ${ }^{13} \mathrm{C}$ NMR, FT-IR, UV/vis DRS, PXRD, and nitrogen sorption analysis, revealing its extremely high stability as a photocatalyst for the evolution of $\mathrm{H}_{2}$ from water reduction. Exceptionally, a slightly declined BET surface area was observed, which was possibly attributed to that the loading of $\mathrm{Pt}$ nanoparticles increased the mass of sample, as well as the pore channels could be blocked after long-time photocatalysis. In the TEM image of $3 \mathrm{wt} \%$ $\mathrm{Pt}$ loaded g- $\mathrm{C}_{40} \mathrm{~N}_{3}$-COF after photocatalytic tests, the dendritic $\mathrm{Pt}$ nanoparticles (DPNs) were found with an average size of $22 \mathrm{~nm}$ $( \pm 2.7 \mathrm{~nm})$ uniformly dispersed over the whole COF matrix (Supplementary Fig. 27a). Each DPN with branching in various directions was consisting of several domains with approximately $3 \mathrm{~nm}$ size, in which the lattice fringes with $d$-spacing of $0.23 \mathrm{~nm}$ with a dihedral angle of $\sim 70^{\circ}$ and $\mathrm{d}$-spacing of $0.2 \mathrm{~nm}$ with a dihedral angle of $\sim 90^{\circ}$ were observed (Supplementary Fig. $28 \mathrm{c}, \mathrm{d}$ ), corresponding to the Pt $\{111\}$ and Pt $\{100\}$ facet, respectively. X-ray photoelectron spectroscopy (XPS) of the Pt loaded g- $\mathrm{C}_{40} \mathrm{~N}_{3}$-COF sample was also recorded. The binding energy of electrons in pyridinyl nitrogen $1 s$ orbital was shifted from $399.5 \mathrm{eV}$ to $399.8 \mathrm{eV}$, indicating that the coordination might occur between Pt and pyridinyl nitrogen atoms (Supplementary Fig. 27b). Pt $4 f$ core level XPS spectra could be deconvoluted into two pairs of peaks corresponding to $\mathrm{Pt}^{0}$ and $\mathrm{Pt}^{2+}$ on the basis of database values (Supplementary Fig. 27c). $\mathrm{Pt}^{0}$ was effective for $\mathrm{H}_{2}$ evolution while $\mathrm{Pt}^{2+}$ confirmed the coordination with pyridinyl nitrogen atom. Reasonably, the formation of such kinds of DPNs were highly associated with the presence of pyridine units in the network of $\mathrm{g}^{-} \mathrm{C}_{40} \mathrm{~N}_{3}$-COF. A few DPNs had ever been achieved by using relatively complicated approaches(e.g., block polymer mediated synthesis) ${ }^{38}$, but seldom found for polymer-based photocatalysts (e.g., g- $\left.\mathrm{C}_{3} \mathrm{~N}_{4}\right)^{39}$. The high surface areas of the resulting DPNs and their intensive interactions with the conjugated backbone of $\mathrm{g}_{-} \mathrm{C}_{40} \mathrm{~N}_{3-}$ COF were beneficial to enhancing photocatalytic activity. The intriguing properties and precise structural information of $\mathrm{Pt}$ loaded $\mathrm{g}_{-} \mathrm{C}_{40} \mathrm{~N}_{3}$-COF, might be available for the further development of ultrahigh performance catalytic systems under the reduced Pt consumption, such as single-atom Pt photocatalyst.

To gain more insights on the active sites of g- $\mathrm{C}_{40} \mathrm{~N}_{3}$-COF for $\mathrm{H}_{2}$ evolution, the reaction process of proton-adsorption-reduction-hydrogen-adsorption was simulated using DFT calculations and the free-energy changes were calculated regarding to two types of nitrogen atom and six carbon atoms of $\mathrm{g}_{-} \mathrm{C}_{40} \mathrm{~N}_{3}$-COF (Fig. 6e). The free-energy variations indicate that site N2 (pyridine- $\mathrm{N}$ ) is favorable for single-site $\mathrm{H}_{2}$ evolution, implying that nitrogen atoms of pyridinyl rings in the network of g- $\mathrm{C}_{40} \mathrm{~N}_{3}$ COF are the dominant active sites for photocatalytic $\mathrm{H}_{2}$ evolution, well in agreement with our previous discussion.

The other two COFs, g- $\mathrm{C}_{31} \mathrm{~N}_{3}-\mathrm{COF}$, and g- $\mathrm{C}_{37} \mathrm{~N}_{3}$-COF were also investigated as photocatalysts for $\mathrm{H}_{2}$ evolution under the same reaction conditions. The preliminary results demonstrate that the $\mathrm{H}_{2}$ evolution rates for $\mathrm{g}-\mathrm{C}_{31} \mathrm{~N}_{3}-\mathrm{COF}$ and $\mathrm{g}-\mathrm{C}_{37} \mathrm{~N}_{3}-\mathrm{COF}$ are 27.1 and $19.8 \mu \mathrm{mol} \mathrm{h}^{-1}$, respectively, which are much lower than that of g$\mathrm{C}_{40} \mathrm{~N}_{3}-\mathrm{COF}$ (Supplementary Fig. 31). Apart from the light-harvesting and charge separation abilities, the crystallinity for these $\mathrm{COF}$ photocatalysts also serve as the crucial role in their photocatalytic activities for water-splitting, likely associated with the defects over the whole networks, as demonstrated by Cooper et al. very recently ${ }^{37}$.

Clearly, achieving an overall water-splitting process using artificial photocatalysts is the ultimate goal in the pursuit of renewable energy sources. Nevertheless, the water oxidation process can be sluggish, presumably due to low driving force and slow $\mathrm{O}-\mathrm{O}$ bond formation kinetics, as observed for the 
representative metal-free photocatalyst $\mathrm{g}-\mathrm{C}_{3} \mathrm{~N}_{4}{ }^{39,40}$. In this study, the water oxidation performance of $\mathrm{g}-\mathrm{C}_{40} \mathrm{~N}_{3}-\mathrm{COF}$ was evaluated using $\mathrm{AgNO}_{3}$ as an electron acceptor and $\mathrm{La}_{2} \mathrm{O}_{3}$ as a $\mathrm{pH}$ buffer under visible-light irradiation. The unmodified $\mathrm{g}-\mathrm{C}_{40} \mathrm{~N}_{3}$-COF sample demonstrated a relatively low $\mathrm{O}_{2}$ production rate of 1.6 $\mu \mathrm{mol} \mathrm{h} \mathrm{h}^{-1}$ (for $50 \mathrm{mg} \mathrm{g}_{-} \mathrm{C}_{40} \mathrm{~N}_{3}$-COF). Loading cobalt species instead of noble metals into the COF samples as cocatalysts could engender a distinct performance enhancement. A low-cost nonnoble metal salt $\mathrm{Co}\left(\mathrm{NO}_{3}\right)_{2}$, as the cobalt source $\left(3 \mathrm{wt} \% \mathrm{Co}^{2+}\right)$, was introduced into the reaction system to modify the catalyst. As illustrated in Fig. 6d, the modified catalyst exhibited visible-light activity $(\lambda>420 \mathrm{~nm})$ for $\mathrm{O}_{2}$ evolution with a rate of $2.5 \mu \mathrm{mol} \mathrm{h}-1$. The resulting oxygen evolution rate is even better than that of bulk g- $\mathrm{C}_{3} \mathrm{~N}_{4}{ }^{12}$. Although the $\mathrm{O}_{2}$ evolution activity of g- $\mathrm{C}_{40} \mathrm{~N}_{3}$-COF was determined to be low, these results directly manifested the thermodynamic possibility of oxygen evolution as a reality. The low activity for $\mathrm{O}_{2}$ evolution might be ascribed to the smaller thermodynamic driving force of such type of COF as compared with that of $\mathrm{H}_{2}$ evolution, which could be further improved by rationally tuning semiconducting properties through precise structural modifications.

\section{Discussion}

Typically, 2D COFs produced through $\mathrm{C}=\mathrm{C}$ linkages possess unique geometric and electronic characteristics because they inherit notable advantages from conventional linear conjugated polymers and $2 \mathrm{D}$ graphene. The intriguing physical properties of these types of polymers render them highly desirable as semiconductors for optoelectronic applications. The traditional concept is that carboncarbon bonds are irreversible and thus could not be used in the construction of highly crystalline structures through a thermodynamic process. Three years ago, we reported an example of a crystalline $\mathrm{COF}$ with cyano-substituted $\mathrm{C}=\mathrm{C}$ linkages, which revealed the reversibility of $\mathrm{C}=\mathrm{C}$ bonds in a Knoevenagel condensation reaction, allowing the formation of highly ordered structures through self-healing processes. In this study, we successfully constructed another family of 2D COFs linked by trans-disubstituted $\mathrm{C}=\mathrm{C}$ bonds through condensation at arylmethyl carbon atoms. The highly crystalline frameworks were clearly revealed by PXRD, HRTEM, and surface area measurements. The frameworks' intrinsic chemical structures, comprising pyridine core networks and neat $\mathrm{C}=\mathrm{C}$ linkages, grant them $\pi$-electron delocalized properties and excellent light-harvesting characteristics. In addition, the appropriate band energy levels render the one of the framework g- $\mathrm{C}_{40} \mathrm{~N}_{3}-\mathrm{COF}$ suitable as a photocatalyst for water splitting with two half-reactions in the presence of sacrificial reagents. A high hydrogen production rate was achieved, namely $206 \mu \mathrm{mol} \mathrm{h}^{-1}$ (relative to $50 \mathrm{mg}$ of COF sample), with the apparent quantum efficiency of $4.84 \%$ at $\lambda=420$ $\mathrm{nm}$. This is among the highest values reported for COF-based photocatalysts so far. An oxygen evolution rate of $2.5 \mu \mathrm{mol} \mathrm{h}^{-1}$ was detected for COF photocatalyst when silver nitrate was applied as an electron acceptor under visible light, comparable to bulk $\mathrm{g}_{-}-\mathrm{C}_{3} \mathrm{~N}_{4}$. One can reasonably foresee that this work provides an approach to scalable and sustainable preparation of excellent $2 \mathrm{D}$ organic semiconductors or organic graphene analogs for potential practical applications far beyond photocatalysis.

\footnotetext{
Methods

Synthesis of $\mathbf{g}-\mathbf{C}_{\mathbf{x}} \mathbf{N}_{\mathbf{y}}-$ COF. All Chemicals were used as received without further purification. First, $0.50 \mathrm{mmol}(85.60 \mathrm{mg})$ of 3,5-dicyano-2,4,6-trimethylpyridine (DCTMP) and $0.75 \mathrm{mmol}(214.74 \mathrm{mg}$ ) of 4,4"-diformyl-p-terphenyl (DFPTP) (or $0.75 \mathrm{mmol}(157.67 \mathrm{mg})$ of $4,4^{\prime}$-diformyl-1,1'-biphenyl (DFBP) or $0.50 \mathrm{mmol}$ (195.22 mg) of 1,3,5-tris(4-formylphenyl)benzene (TFPB)) were placed in a $15-\mathrm{mL}$ pressure flask. Then it was transferred into an argon-filled glovebox, where 3.00 mmol $(255.45 \mathrm{mg})$ piperidine and $10 \mathrm{~mL}$ anhydrous deoxygenated $\mathrm{N}, \mathrm{N}$-dimethylformamide (DMF) were added. The mixture was stirred in glovebox for $5 \mathrm{~min}$ to dissolve the solid monomers into DMF. Then the pressure flask was sealed by
}

Teflon nut and taken out from glovebox. Subsequently, the clear homogenous paleyellow solution was heated in a $150{ }^{\circ} \mathrm{C}$ oil bath for 3 days. After cooling to room temperature, yellow precipitates were observed at the bottom of flask, leaving clear and colorless supernatant. The precipitate was filtered and washed by acetone and dichloromethane for several times, and then it was dried under vacuum for $12 \mathrm{~h}$ at $120^{\circ} \mathrm{C}$. Finally, yellow powder was obtained and the yield based on monomers was calculated to be approximately $99.3 \%$.

Photocatalytic hydrogen evolution. A flask was charged with $50 \mathrm{mg}$ of g- $\mathrm{C}_{40} \mathrm{~N}_{3^{-}}$ COF powder, $100 \mathrm{~mL}$ deionized water and $10 \mathrm{~mL}$ triethanolamine (TEoA). It was ultrasonicated for $15 \mathrm{~min}$ to obtain a well-dispersed suspension. Then the resulting suspension was transferred into a Pyrex top-irradiation reaction vessel connected to a closed gas system. Certain amount of platinum $(\mathrm{Pt})$ as cocatalyst was loaded into the network of photocatalyst by in situ photodeposition method using $\mathrm{H}_{2} \mathrm{PtCl}_{6}$. The reaction mixture was evacuated several times to ensure complete removal of air prior to irradiation in a $90^{\circ}$ angle with a $300 \mathrm{~W}$ Xe light-source. The wavelength of the incident light was controlled by using a $420 \mathrm{~nm}$ long pass cut-off filter. The temperature of the reaction solution was maintained at $12{ }^{\circ} \mathrm{C}$ by the flow of cooling water. The evolved gases were analyzed by gas chromatography equipped with a $5 \AA$ molecular sieve column at $60^{\circ} \mathrm{C}$ with argon as the carrier gas Hydrogen was detected with a thermal conductivity detector (TCD) referencing against standard gas with a known concentration of hydrogen. Hydrogen dissolved in the reaction mixture was not measured and the pressure increase generated by the evolved hydrogen was neglected in the calculations. The hydrogen evolution rates were determined from a linear regression fit.

Photocatalytic oxygen evolution. Fifty miligram of g- $\mathrm{C}_{40} \mathrm{~N}_{3}-\mathrm{COF}$ was well dispersed by ultrasonication in an aqueous solution $(100 \mathrm{~mL})$ containing $0.01 \mathrm{~mol} \mathrm{~L}^{-1}$ $\mathrm{AgNO}_{3}$ as an electron acceptor and $0.2 \mathrm{~g} \mathrm{La}_{2} \mathrm{O}_{3}$ as a pH buffer. The suspension was poured into a Pyrex top-irradiation reaction vessel connected to a closed gas system. Then it was evacuated several times to completely remove air prior to irradiation under a $300 \mathrm{~W}$ Xe lamp. The temperature of the reaction solution was maintained at $12{ }^{\circ} \mathrm{C}$ by the flow of cooling water. The evolved gases were analyzed by gas chromatography equipped with a $5 \AA$ molecular sieve column at $60^{\circ} \mathrm{C}$ with argon as the carrier gas. Oxygen was detected with a thermal conductivity detector (TCD) referencing against standard gas with a known concentration of oxygen.

The apparent quantum yield (AQY) measurements. The apparent quantum yield (AQY) for $\mathrm{H}_{2}$ evolution was measured using monochromatic LED lamps with band pass filter of $420 \pm 4.6 \mathrm{~nm}, 470 \pm 4.4 \mathrm{~nm}, 490 \pm 3.8 \mathrm{~nm}, 520 \pm 4.0 \mathrm{~nm}, 578 \pm$ $4.1 \mathrm{~nm}$ (errors of wavelength were depended on Guass Simulation of full width at half maximum), the intensities were $14.3,11.2,7.6,2.9,1.6 \mathrm{~mW} \mathrm{~cm}^{-1}$, respectively (ILT 950 spectroradiometer). The irradiation area was controlled as $3 \times 3 \mathrm{~cm}^{2}$. Depending on the amount of hydrogen produced by the photocatalytic reaction in one hour, the AQY was calculated according to Eq. (1):

$$
\begin{aligned}
& \eta_{\mathrm{AQY}}=\frac{\mathrm{N}_{\mathrm{e}}}{\mathrm{N}_{\mathrm{p}}} \times 100 \% \\
& =\frac{2 \times M \times N_{A}}{\frac{E_{\text {total }}}{\bar{F}_{\mathrm{photon}}}} \times 100 \% \\
& =\frac{2 \times M \times N_{A}}{\frac{S \times P \times x}{\mathrm{~h} \times \mathrm{T}}} \times 100 \% \\
& =\frac{2 \times M \times N_{A} \times h \times c}{S \times P \times t \times \lambda} \times 100 \%
\end{aligned}
$$

Where, $\mathrm{N}_{\mathrm{e}}$ is the amount of generated electrons, $\mathrm{N}_{\mathrm{p}}$ is the incident photons, $M$ is the amount of $\mathrm{H}_{2}$ molecules (mol), $N_{A}$ is Avogadro constant $\left(6.022 \times 10^{23} \mathrm{~mol}^{-1}\right)$, $h$ is the Planck constant $\left(6.626 \times 10^{-34} \mathrm{~J} \cdot \mathrm{s}\right), c$ is the speed of light $\left(3 \times 10^{8} \mathrm{~m} \mathrm{~s}^{-1}\right), S$ is the irradiation area $\left(\mathrm{cm}^{2}\right), P$ is the intensity of irradiation light $\left(\mathrm{W} \mathrm{cm}^{-2}\right), t$ is the photoreaction time $(\mathrm{s}), \lambda$ is the wavelength of the monochromatic light $(\mathrm{m})$.

\section{Data availability}

All data supporting the findings of this study are available within the article, as well as the Supplementary Information file, or available from the corresponding authors on reasonable request.

Received: 21 October 2018 Accepted: 13 May 2019

Published online: 06 June 2019

\section{References}

1. Perepichka, D. F. \& Rosei, F. Extending polymer conjugation into the second dimension. Science 323, 216-217 (2009).

2. Ebrahimi, M. \& Rosei, F. Organic analogues of graphene. Nature 542, 423 (2017).

3. Colson, J. W. \& Dichtel, W. R. Rationally synthesized two-dimensional polymers. Nat. Chem. 5, 453 (2013). 
4. Burroughes, J. H. et al. Light-emitting diodes based on conjugated polymers. Nature 347, 539 (1990).

5. Greenham, N. C., Moratti, S. C., Bradley, D. D. C., Friend, R. H. \& Holmes, A. B. Efficient light-emitting diodes based on polymers with high electron affinities. Nature 365, 628 (1993).

6. Moreno, C. et al. Bottom-up synthesis of multifunctional nanoporous graphene. Science 360, 199-203 (2018).

7. Liu, W. et al. A two-dimensional conjugated aromatic polymer via C-C coupling reaction. Nat. Chem. 9, 563 (2017).

8. Zhuang, X. et al. A two-dimensional conjugated polymer framework with fully $s p^{2}$-bonded carbon skeleton. Polym. Chem. 7, 4176-4181 (2016).

9. Uribe-Romo, F. J. et al. A crystalline imine-linked 3-D porous covalent organic framework. J. Am. Chem. Soc. 131, 4570-4571 (2009).

10. Jin, E. et al. Two-dimensional $\mathrm{sp}^{2}$ carbon-conjugated covalent organic frameworks. Science 357, 673-676 (2017).

11. Zimmerman, H. E. \& Ahramjian, L. Overlap control of carbanionoid reactions. II. ${ }^{1}$ The stereochemistry of the perkin reaction and related condensation reactions. J. Am. Chem. Soc. 81, 2086-2091 (1959).

12. Wang, X. et al. A metal-free polymeric photocatalyst for hydrogen production from water under visible light. Nat. Mater. 8, 76 (2008).

13. Sprick, R. S. et al. Tunable organic photocatalysts for visible-light-driven hydrogen evolution. J. Am. Chem. Soc. 137, 3265-3270 (2015).

14. Zhang, G., Lan, Z.-A. \& Wang, X. Conjugated polymers: catalysts for photocatalytic hydrogen evolution. Angew. Chem. Int. Ed. 55, 2-18 (2016).

15. Yanagida, S., Kabumoto, A., Mizumoto, K., Pac, C. \& Yoshino, K. Poly(para) phenylene-catalyzed photoreduction of water to hydrogen. J. Chem. Soc. Chem. Commun. 8, 474-475 (1985).

16. Shibata, T. et al. Novel visible-light-driven photocatalyst. Poly(p-phenylene)catalyzed photoreductions of water, carbonyl compounds, and olefns. J. Phys. Chem. 94, 2068-2076 (1990).

17. Schwab, M. G. et al. Photocatalytic hydrogen evolution through fully conjugated poly(azomethine) networks. Chem. Commun. 46, 8932 (2010).

18. Yang, C. et al. Molecular engineering of conjugated polybenzothiadiazoles for enhanced hydrogen production by photosynthesis. Angew. Chem. Int. Ed. 55, 9202-9206 (2016).

19. Sprick, R. S. et al. Extended conjugated microporous polymers for photocatalytic hydrogen evolution from water. Chem. Commun. 52, 10008-10011 (2016).

20. Sprick, R. S. et al. Visible-light-driven hydrogen evolution using planarized conjugated polymer photocatalysts. Angew. Chem. Int. Ed. 55, 1792-1796 (2016).

21. Stegbauer, L., Schwinghammer, K. \& Lotsch, B. V. A hydrazone-based covalent organic framework for photocatalytic hydrogen production. Chem. Sci. 5, 2789-2793 (2014).

22. Vyas, V. S. et al. A tunable azine covalent organic framework platform for visible light-induced hydrogen generation. Nat. Commun. 6, 8508 (2015)

23. Banerjee, T. et al. Single-site photocatalytic $\mathrm{H}_{2}$ evolution from covalent organic frameworks with molecular cobaloxime Co-catalysts. J. Am. Chem. Soc. 139, 16228-16234 (2017).

24. Pachfule, P. et al. Diacetylene functionalized covalent organic framework (COF) for photocatalytic hydrogen generation. J. Am. Chem. Soc. 140, 1423-1427 (2018).

25. Wei, P.-F. et al. Benzoxazole-linked ultrastable covalent organic frameworks for photocatalysis. J. Am. Chem. Soc. 140, 4623-4631 (2018).

26. Rao, M. R., Fang, Y., De Feyter, S. \& Perepichka, D. F. Conjugated covalent organic frameworks via Michael addition-elimination. J. Am. Chem. Soc. 139, 2421-2427 (2017).

27. Friend, R. H. et al. Electroluminescence in conjugated polymers. Nature $\mathbf{3 9 7}$, 121 (1999).

28. Ng, S.-C. et al. Blue electroluminescence from a novel donor/acceptor polymer structure. Adv. Mater. 12, 1122-1125 (2000).

29. Attias, A.-J. et al. Columnar mesophase from a new disclike mesogen based on a 3,5-dicyano-2,4,6-tristyrylpyridine core. Chem. Mater. 14, 375-384 (2002).

30. Wang, H. et al. Synthesis and properties of new two-photon absorption chromophores containing 3,5-dicyano-2,4,6-tristyrylpyridine as the core. New J. Chem. 29, 792-797 (2005).

31. Peng, Y. et al. Ultrathin two-dimensional covalent organic framework nanosheets: preparation and application in highly sensitive and selective DNA detection. J. Am. Chem. Soc. 139, 8698-8704 (2017).

32. Dalapati, S., Jin, E., Addicoat, M., Heine, T. \& Jiang, D. Highly emissive covalent organic frameworks. J. Am. Chem. Soc. 138, 5797-5800 (2016).

33. Zhang, T. et al. Copper-surface-mediated synthesis of acetylenic carbon-rich nanofibers for active metal-free photocathodes. Nat. Commun. 9, 1140 (2018).
34. Zhang, Y. \& Antonietti, M. Photocurrent generation by polymeric carbon nitride solids: an initial step towards a novel photovoltaic system. Chem. Asian J. 5, 1307-1311 (2010).

35. Bian, J. et al. Efficiency enhancement of carbon nitride photoelectrochemical cells via tailored monomers design. Adv. Energy Mater. 6, 1600263 (2016).

36. $\mathrm{Bi}$, S. et al. Substantial cyano-substituted fully $s p^{2}$-carbon-linked framework: metal-free approach and visible-light-driven hydrogen evolution. Adv. Funct. Mater. 27, 1703146 (2017).

37. Wang, X. et al. Sulfone-containing covalent organic frameworks for photocatalytic hydrogen evolution from water. Nat. Chem. 10, 1180-1189 (2018).

38. Wang, L. \& Yamauchi, Y. Block copolymer mediated synthesis of dendritic platinum nanoparticles. J. Am. Chem. Soc. 131, 9152-9153 (2009).

39. Maeda, K. et al. Photocatalytic activities of graphitic carbon nitride powder for water reduction and oxidation under visible light. J. Phys. Chem. C. 113, 4940-4947 (2009)

40. Lan, Z.-A., Fang, Y., Zhang, Y. \& Wang, X. Photocatalytic oxygen evolution from functional triazine-based polymers with tunable band structures. Angew. Chem. Int. Ed. 57, 470-474 (2018).

\section{Acknowledgements}

We thank Shanghai Committee of Science and Technology for financial support within the project $16 \mathrm{JC1} 1400703$. Furthermore, this work was financially supported by National Natural Science Foundation of China (21720102002, 21774072, 21574080, 21425309, 21761132002, 21861130353, and 21802022), the National Key Technologies R\&D Program of China (2018YFA0209301) and the 111 Project (D16008). Open Project Program of the State Key Laboratory of Inorganic Synthesis and Preparative Chemistry (2019-01, Jilin University). S.B. acknowledges the Instrumental Analysis Center of SJTU for the NMR measurements. We thank Professor Feng Liu for his precious help.

\section{Author contributions}

F.Z. and X.W. conceived and designed the experiments. S.B. performed the experiments and carried out the structural characterizations. C.Y. helped to analyze the results of photocatalytic experiments. W.Z. and D.W. helped with the structural characterization analysis. J.X. helped to synthesize the materials. L.L. and Y.H. helped to perform the high resolution TEM measurements. Q.L. performed the DFT calculations. S.B. and F.Z. wrote the manuscript with contributions from all the authors.

\section{Additional information}

Supplementary Information accompanies this paper at https://doi.org/10.1038/s41467019-10504-6.

\section{Competing interests: The authors declare no competing interests.}

Reprints and permission information is available online at http://npg.nature.com/ reprintsandpermissions/

Journal peer review information: Nature Communications thanks the anonymous reviewer(s) for their contribution to the peer review of this work.

Publisher's note: Springer Nature remains neutral with regard to jurisdictional claims in published maps and institutional affiliations.

(i)

Open Access This article is licensed under a Creative Commons Attribution 4.0 International License, which permits use, sharing, adaptation, distribution and reproduction in any medium or format, as long as you give appropriate credit to the original author(s) and the source, provide a link to the Creative Commons license, and indicate if changes were made. The images or other third party material in this article are included in the article's Creative Commons license, unless indicated otherwise in a credit line to the material. If material is not included in the article's Creative Commons license and your intended use is not permitted by statutory regulation or exceeds the permitted use, you will need to obtain permission directly from the copyright holder. To view a copy of this license, visit http://creativecommons.org/ licenses/by/4.0/.

(C) The Author(s) 2019 